\title{
Worlds Apart: Experiences of Students Learning Chinese as Foreign Language in Universities in China and South Africa
}

\author{
Dr Yuhua Wang Qi \\ University of South Africa \\ Email: yhqwang@gmail.com \\ Prof EM Lemmer \\ College of Education, University of South Africa \\ Email: lemmeem@unisa.ac.za
}

\section{Doi:10.5901/mjss.2014.v5n15p414}

\begin{abstract}
Due to the prominent position China holes in the global economy, there is now an increasing demand, worldwide, to learn Chinese as a foreign language. However, most non-native speakers regard CFL as a very difficult language to master. This paper presents the findings of a qualitative inquiry into student experiences of CFL study in universities in China and South Africa. CFL programmes offered by a substantial number of Chinese universities are well-established and provide foreign students who want to study CFL with an attractive opportunity. In South Africa, the progressive development of CFL programmes, currently offered by four major universities, has been modest but steady. Using an interpretative approach, this paper explores (through in-depth interviews) the lived experiences of two groups of full-time CFL students in different sociolinguistic settings. Participants were chosen using purposeful sampling carried out in three selected universities in China and the four South African institutions mentioned above. The results identify differences in course delivery, classroom communication and language support outside the classroom. Despite the differences created by the widely differing contexts of CFL acquisition in China and in South Africa, participants shared similar experiences regarding emotional dimensions of language learning, academic 'push and pull' and specific difficulties of CFL acquisition. The paper concludes with a discussion of findings and recommendations to enhance CFL in both contexts.
\end{abstract}

Keywords: Chinese as Foreign Language, South Africa, China, higher education, qualitative research, interviews

\section{Introduction}

China's role as a world economic power has led to a growing interest in the country and a significant demand to learn Mandarin Chinese as a second, foreign or additional language by non-native speakers throughout the world (Wang, Maloney \& Li 2013). This fact is illustrated by increasing enrolments of non-native speakers in Chinese Foreign Language (CFL) courses and admission to the Chinese Proficiency Test: Hanyu Shuiping Kaoshi (HSK), the national standardized test of Chinese language proficiency for non-native speakers. There is also an increasing demand for competent teachers of Chinese both inside and outside China. At present, there are more than 400 universities and colleges offering various CFL programmes to foreign learners; in addition to the traditional preparatory type of CFL programme, undergraduate, postgraduate and intensive short-term CFL courses are available to non-native speakers (Lu \& Zhao 2011).

A similar interest in CFL is also observable in South Africa, a country geographically and culturally worlds apart from China (Wang \& Lemmer 2013; Wang 2013). South Africa has a very small Chinese-speaking community, estimated at between 350000 to 500000 (Park 2012) out of a population of 53 million residents (Statistics South Africa 2013). No specific policy underlies the introduction of CFL into higher education curricula, although the motivation for CFL provision in this context is associated with strategic trade relations, initially between South Africa and Taiwan in the early 1990s, and today between South Africa and China itself. At present, three prestigious South African universities offer CFL at first, second- and third-year levels in their undergraduate degree programmes: Rhodes University, the University of Cape Town and the University of South Africa (Unisa). Unisa is the largest distance education university in southern Africa and CFL tuition is through printed or electronic instructional material complemented by audio-recordings. A fourth major university, Stellenbosch University, an Afrikaans-medium institution, offers both an undergraduate as well as a postgraduate degree in CFL (Wang 2013). Curricula documents and marketing material of the respective institutions use 
the terms Chinese, Mandarin or Mandarin Chinese differently; the nomenclature used by a specific institution has therefore been used, where applicable, in this paper. Elsewhere, the umbrella term 'Chinese' has been used to refer to the standard language spoken in China (Lytra \& Martin 2010); the term 'Chinese as a Foreign Language' (CFL) is used to refer to Chinese as acquired by non-native speakers. Finally, three of the four mentioned South African universities, Stellenbosch, Rhodes and Cape Town, enjoy the support provided by a Confucius Institute (i.e. a non-profit Chineselanguage learning institution established and funded by the Hanban) on their campuses (Feng 2008).

China and South Africa present two very different national and sociolinguistic contexts for CFL learning. This paper reports on a qualitative inquiry which explored the lived experiences of students enrolled in CFL programmes in selected universities in China and South Africa (Wang 2013).

\section{Conceptual Framework}

Generally speaking, the literature does not make a distinction between a foreign language (FL) and a second language $(\mathrm{SL})$; the terms are either used interchangeably or foreign language is subsumed under the term 'second language' (Healy 1998; Saville-Troike 2012). This variability in terminology can be observed in the alternative terms (not necessarily synonymous) used by different authors when referring to standard Chinese as acquired by non-native speakers, such as, Chinese as a Second Language (CSL), Chinese as a Foreign Language (CFL), Chinese Mandarin as a Foreign Language (CMFL) and Mandarin as a Foreign Language (MFL). Distinctions drawn between second language versus foreign language can be useful when discussing language pedagogy. Fashold and Connor-Linton (2006) distinguish between additional languages learned with reference to a speech community, which is outside (termed an FL) or inside (termed an SL) the national or territorial boundaries in which the language learning takes place. Added to this geographical marker of an FL or an SL, Crystal (2010) adds the domains of use and of status as differentiating features. An SL is a language, other than mother tongue or first language, used in a country for a special purpose in a specific domain(s). An example is an SL which is used as the medium of instruction in the education system or in government; this type of SL enjoys a high status owing to its use in the key domains of society. An FL lacks this special internal function in specific domains and the accompanying status in a particular society. A further distinction lies in the motivation for learning an FL versus an SL: an FL is usually learned for the purposes of travel, communication with native speakers and access to written content, such as literature or technical material, in the said language; in contrast, learning an SL is essential for a person's optimal participation in a multilingual country (Richards \& Schmidt 2002). In the light of this discussion and in the context of this paper, in English-speaking countries, such as the United States, Britain and Australasia, Chinese can be understood as an $\mathrm{FL}$ and one with an exceptionally high degree of difficulty for non-native speakers with an alphabetic background (Xu, Chang, Zhang \& Perfetti 2013). In the same countries, English is an SL for non-English citizens who require English in order to participate fully in society.

Likewise, the terms 'second language acquisition' (SLA) and 'foreign language acquisition' (FLA) tend to be used interchangeably in the literature, with an overwhelming preference for the term SLA among Western scholars (Healy 1998). Where SLA and FAL are indeed distinguished, the relationship is seen primarily as unidirectional, whereby theory flows from SLA acquisition and pedagogy to FLA acquisition and pedagogy. Thus, FLA is seen as a subset of SLA and whatever is true for SLA is applicable to FLA, but not vice versa (Van Patten 1990; Van Patten \& Williams 2007). This generalised transference of SLA theory and practice has led to an oversimplified picture of the many differences and complexities embedded in FLA learning and teaching. In the light of this, Siegel's (2007) sociolinguistic theory of social context was deemed appropriate as a theoretical framework for this study. Although Siegel (2007) relies on SL rather than FL as a general term, he makes a useful distinction among different language learning settings. Siegel (2007) identifies five broad sociolinguistic settings for SLA. Firstly, in the dominant SL setting, the SL is actually the mother tongue of the majority of the population and is used in all domains of everyday life: home, education system, government, law, commerce and the media. SL learners may be immigrants or indigenous minorities who are motivated to acquire the dominant language in order to engage in mainstream society; these people encounter substantial exposure to the SL outside the classroom. Secondly, in the external SL setting, SL learners are usually language speakers of the dominant language group who, for a host of reasons, wish to acquire a language not generally used within their society. This may be a foreign language, a language spoken in a distant part of the same country or a world language; in this case, learners have limited exposure to the SL outside of the classroom. Thirdly, in a coexisting SL setting, the SL coexists with the dominant language and is spoken in the immediate or nearby environment by a large proportion of the population. Both languages are used in similar domains by their respective speakers and enjoy similar status; thus, learners will find substantial exposure to the SL outside the classroom. Fourthly, in the institutional SL setting, the SL is widely used in the public domains and institutions, and learners acquire the SL while retaining mother tongue for private use. Fifthly, in the 
minority $S L$ setting, dominant language speakers wish to learn a minority language spoken by a small group in society mainly for purpose of intergroup communication. In all five settings the effectiveness of SL language acquisition by SL learners is influenced by the socio-linguistic context. This context consists of several factors, among which is exposure to the target language and the opportunity to communicate in natural language settings independent of formal tuition and study.

Siegel's sociolinguistic settings can be linked to a very wide variety of models of SLA (and hence FLA) programmes (Baker 2001; 2007; Garcia 2009; Mackey 2008; Siegel 2007). To discuss all these ramifications is beyond the scope of this paper; in this paper, we shall deal only with the rough distinction between monolingual and bilingual programmes based on the medium of instruction. Bilingual programmes, in which L1 and the SL both function strongly, are most common in dominant SL settings and in institutional SL settings where SL acquisition is essential for full social participation. Monolingual programmes include two sub-models: L1 and SL monolingual programmes. In L1 monolingual programmes, the SL is the subject of formal study, but the medium of instruction is the L1 of all (or most) learners. This is typically found in external SL settings. In SL monolingual programmes, the SL is both the medium of instruction and the subject of formal study and this is typical of dominant SL settings (Siegel 2007). Apart from type of programme, effective $\mathrm{SL}$ or $\mathrm{FL}$ study requires formal classroom instruction combined with ample informal language learning that occurs through natural communication with native speakers outside the classroom. In this regard, FL language study through immersion in a community of native speakers provides this ideal combination (Freed 1995; Collentine \& Freed 2004). Several studies highlight the optimisation of language learning through study abroad in the country of the target language. (Dewey; 2008; Sasaki2009; Freed \& Lazar 2003).

\section{Method}

Against this background, our interpretative design explored the lived experiences of CFL students enrolled in universities in South Africa and in selected universities in China. Participants comprised 33 full-time students of CFL: 19 participants were engaged in study in China and 14 in South Africa. Participants were selected by purposeful sampling (McMillan \& Schumacher 2010) according a predefined criterion: full-time enrolment in a CFL course at the respective institutions (although the nomenclature of the courses and the levels of study in which participants were engaged varied from institution to institution). Purposeful sampling allows the identification of students who would be able to provide rich and varied insights into a topic of inquiry which has been hitherto little researched (Wang 2013). Since participants were not chosen in order to produce a sample representative of the larger population, but to represent a range of students with different backgrounds and experience, no attempt was made to generalise findings.

CFL students in China hailed from 12 different countries: Israel, the United States, Sweden, Italy, Russia, Spain, Turkey, Thailand, South Korea, Indonesia, Japan and Vietnam. All were L1 speakers of the dominant/only language spoken in their home countries. The majority were females (12) in comparison with seven males. Most participants (12) were studying CFL for non-degree purposes; five were studying for the four-year B degree (with a dedicated CFL focus) and two for the Master's degree. Fourteen (14) participants had had at least six months' CFL study in her/his home country; five students were beginners. CFL students in South Africa were all South African citizens but reflected the country's linguistic diversity: twelve were L1 English-speakers; four were L1 Afrikaans-speakers; one was an L1 Xhosaspeaker. The majority were female (10) in comparison with four males. Twelve (12) students were enrolled for the threeyear B degree (in which CFL can be chosen as a major but functions with several unrelated electives) and two participants were enrolled for CFL courses for non-degree purposes (concurrently with studying for other degrees). A postgraduate degree in CFL in South Africa was not possible at the time of the study (although this is now possible) and was therefore not represented. Participants in both China and South Africa fell in the age group $18-35$ years.

Data was collected by semi-structured interviews conducted in China during a dedicated study visit (June 2012) and in South Africa (September to October 2012) in the natural setting of the university campus or at the student's or chief researcher's home (according to participant preference). A brief questionnaire recorded biographical information. The research purpose and process of data collection were explained and participation was voluntary, anonymous and confidential. In the data presentation pseudonyms are used to identify participant quotations. The chief researcher (Wang) used a flexible interview schedule to cover topics identified in the literature and in CFL curricula and course material of the participating universities. Interviews were conducted in the language preferred by the participants: in China all participants elected to use Chinese; in South Africa all participants elected to use English. Interviews were digitally recorded; the chief researcher's lengthy experience as a CFL teacher/lecturer in China and in South Africa and the participants' enthusiasm for the topic created a rapport which definitely helped to ensure that the data collected was authentic. Verbatim interview transcripts were made and interviews conducted in Chinese were translated into English for 
analysis and reporting. Data analysis took place during and after data collection. Analytic guidelines for grounded theory (Charmaz 2011) were used with a certain degree of flexibility.

\section{Findings}

Six main themes were identified: course delivery, classroom communication and language support outside the classroom. These themes are related to striking differences in student experiences of CFL in the two contexts. The remaining three themes were: emotional dimensions of language learning, academic 'push and pull' and particular difficulties of CFL acquisition; these themes relate to commonalities in student experiences of CFL in the two contexts.

\subsection{Course delivery}

All participants interviewed in China were full-time students engaged in the study of CFL as their only subject. Participants attended about 20 to 24 formal hours of CFL tuition in the mornings at their respective institutions from Monday to Friday. Excluding the Master's programme, CFL was presented according to four basic components which match the four language skills: listening, speaking, reading and composition. Each skill was presented in different classes (or parts of classes). In addition, a comprehensive class was presented in which grammar is taught; this class was usually presented by a senior (best qualified and experienced) lecturer. This CFL teaching model is common to most institutions in China (Lu \& Zhao 2011). In B-degree programmes, other subjects in addition to the major all relate to the learning of Chinese or Chinese culture in different domains. The programme thus has a dedicated focus on CFL. Participants attended classes in a lecture room/classroom used exclusively for CFL tuition and the décor of classrooms promoted CFL learning. Brightly coloured posters encouraged students to speak Chinese rather than their mother tongue and drew students' attention to informative articles or movies. CFL class attendance was stable and a class representative facilitated contact among students and between students and lecturers. The annual enrolment of CFL students in degree and non-degree programmes is stable and this encourages the formation of close relationships among classmates who become a language 'family.' CFL students hold social functions regularly. As one participant commented: "We have a very good relationship between classmates; we will have a party tonight for my birthday."

All participants interviewed in South Africa were full-time students in a three-year undergraduate B-degree programme and were studying CFL as one of several electives. A language such as Chinese may be chosen as an undergraduate major, but this is in addition to other unrelated electives. Thus, the dedicated focus on CFL and Chinese culture is lacking. Tuition time ranged between 3 to 5 hours per week plus 1 or 2 hours of oral practice. Classes were not scheduled strictly in the mornings; they might be scheduled as late as 16:00-17:00h when students were tired and less able to engage in strenuous FL study. Courses were comprehensive or integrated and separate classes were not offered to develop oral, listening, reading and composition skills. In all institutions, CFL was taught in a multipurpose lecture room where permanent displays are simply not practicable. Class attendance was not stable, particularly with regard to language tutorials, owing to timetable clashes with lectures on other subjects. A system of class representatives was lacking. Student enrolments were erratic, with striking differences in enrolments between the first-year, the second-year and the third-year courses; numbers decline drastically as the levels increase. As one participant, Nosi, reported: "We had 60 students in the first year, which was a lot. But there were 20 last semester. And in this semester, it is about 12. The more difficult it gets, the more people pull back and drop out."

In addition to formal classroom tuition, CFL participants in China enjoyed the advantage of peer tutors to support language learning. In the case of two universities represented by the participants, a formal system of peer tutoring has been organised. Ajiao, an Indonesian student, described the peer tutor-student relationship: "We have a tutor. The time is not the same every day, it depends. We do not need to pay; the university helps us to study with tutors after class. At least one hour per day." Where a peer tutor was not assigned by the university, finding a suitable peer tutor in the community was not difficult. "I can find Chinese friends easily to chat with on our campus and help me with homework", Swedish student Greta commented. Thus, peer tutoring in the Chinese context includes but is not limited to formal university arrangements. Tutors are native-speaking Chinese nationals of approximately the same age as participants who are positively inclined to chat with their new foreign friends and share their lives within both social and university contexts. South Africa universities, with the exception of Unisa, the distance education university, also appoint at least one tutor in addition to the lecturer to assist or supervise students particularly with a view to the development of students' oral skills. However, the tutor is an CFL lecturer or a suitable teacher appointed from outside the university, not a fellow student. Furthermore, tutoring occurs during a formal tutorial class held for one to two hours per week for all CFL students. Where participants do not attend tutorials owing to timetabling clashes, it is very difficult to identify a Chinese- 
speaking peer to fulfil the tutor role. Jill mentioned: "It is difficult to find someone who can speak Mandarin. No Chinese friends." Even those students who have Chinese-speaking friends find it challenging to persuade them to converse in Chinese. Joy, a first-year CFL student, commented: "I do struggle. I have a few Chinese friends and Taiwanese friends [who have been born and/or raised in South Africa] but most of them do not really speak Chinese or Taiwanese [sic]. If I speak Chinese, they will say, 'Why do you speak this? You can speak English!' "Thus, friends also prefer the easier option of speaking English when interacting socially.

\subsection{Classroom communication}

According to participants in China, Chinese is used as the sole medium of instruction during tuition. Only at the outset of an introductory course did lecturers use English as medium of instruction, and only for a very short time. Opinions over this issue were diverse: some students felt code-switching between English and Chinese was helpful at the beginning of introductory courses. But once beginner students gained some proficiency, they appreciated the use of Chinese as the only medium of instruction. Huizi, a third-year B-degree student who was majoring in tourism in her home country, Thailand, was in China for short-term language study. She noted: "Three lecturers cannot speak English, not even one word, but others used English [in the beginning]. I don't like my lecturers to speak English. I have come to study Chinese not English. I prefer my lecturers to use Chinese so I can remember it." American classmate, Joe, who was engaged in postgraduate studies and who had already completed a four-year degree with Chinese as a major in the US, agreed: "I prefer the lecturer to use the target language [Chinese] to teach. But the Chinese language is really different from other European languages so it is necessary to use English, my home language, sometimes". Furthermore, in China where CFL classes consist of a mix of international students, Chinese is perforce the medium of social interaction among students in the classroom. Vietnamese student, Amei, who is enrolled in a Master's programme, commented: "Our classmates come from six different countries so we must use Chinese to communicate with each other. We speak in Chinese in the classroom, in the student dormitory, at any time when we need to chat."

In South Africa, English is the medium of instruction during CFL tuition at all four institutions. Lecturers start to use Chinese as medium of instruction very gradually in the second- and third year levels. Linda, a first-year student with six month's study experience, said: "My lecturer uses English. Sometime she uses some Chinese phrases but at this time we are not good enough to use Chinese. I hear that in the third year, they speak Chinese. I think we need to become good enough then the lecturer can also speak Chinese." Although already in his third year of study, Tony made the same point: "They [lecturers] try to speak Mandarin but we do not know enough so they have to speak English. The other lecturer [of Mandarin] uses German. She used to live in Germany so she normally uses either English or German." Furthermore, in South Africa, social interaction among students in the classroom is in English or, at times, in Afrikaans. One participant noted: "We use English. We never speak Chinese after class. Sometimes we practise for an oral but that is maybe once a day, so it is not common."

Pertinently, those participants interviewed in China who had commenced CFL study in their home countries prior to studying abroad in China made the same observations as the South African participants. Students reported that, at institutions in the home country, it was also common to use the L1 (or dominant language) of the respective country as the only medium of instruction during CFL lessons. Amei, who came from Vietnam, remarked: "My teacher used mother tongue [Vietnamese] in Vietnam...our textbooks were in English. Most of the time teachers used Vietnamese to teach." Shana, an Israeli enrolled in the Masters programme in Chinese, reflect on her undergraduate study back home: "In Israel, Chinese lecturers used Israeli to teach CFL; they were powerful!” [meaning their bilingualism was impressive].

\subsection{Language acquisition outside the classroom}

Students interviewed in China reaped the benefits of immersion in a natural language environment outside the classroom. Not only did they get ample opportunity to practise conversational skills in the local Chinese community, but they were also introduced to popular Chinese culture: lifestyle, cuisine and customs. They picked this up informally during their dayto-day lives and did not rely on textbook information. Joe, the American, told his story of cultural immersion: "An unforgettable experience took place when, during the spring festival, my friend took me to his hometown in Guizhou province. His home was in a village and that was the first time I experienced village life in China. I saw some people who are not educated and I grasped something of real life in China. I was touched by the local customs. I could never learn this from a textbook." All the participants confirmed that living and studying CFL in China was like living in an immense language laboratory: conversational skills are rapidly acquired, contextual understanding is developed and vocabulary is increased. Participants commented on the willingness of fellow students, service people or even strangers to converse 
with them in Chinese without any regard for their faltering attempts to use Chinese. This is a huge benefit and adds to enjoyment of language learning.

In contrast, the experience of most CFL students in South Africa is a lonely one. Although students reported that they devoted considerable time to the intensive study of formal course material, they felt isolated. Firstly, this sense of Ioneliness was felt in the classroom, where the relationship among the CFL students was not close. Since the students are involved in different study programmes and different subjects, they meet only once a day for a CFL lecture of roughly 40 minutes and do not form a cohesive group. CFL students who studied through distance education (Unisa) had little, if any, chance of forming classroom-based friendships. Annie, who has been studying CFL for two years through distance education, is intensely interested in Chinese study and her enjoyment is apparent. However, she said: "I do not know other students. I only see them during the exam sessions. There were two rows of desks for Mandarin students and I have never had contact with any others." Secondly, as we have already mentioned, in South Africa it is very difficult for CFL students to find a conversational partner(s) after class. Pease is a second- year CFL student who remarked: "Many South Africans do not know China well. If I tell my friends that I am studying Chinese, they ask, 'What is Chinese?' They also feel there is only one country in the East. They do not distinguish between China, Taiwan and Hong Kong. It is difficult. It's like I am studying alone." Another participant, Peter, has studied CFL diligently for more than ten years at language schools, with private tutors and through formal university study. Yet his feeling of isolation was more intense than that of the other students. He said:

This is what makes me so sad. This eventually made my learning very slow. The journey is very lonely in South Africa. It is very, very lonely! Learning Mandarin is the mountain that no one else wants to climb...and the question is: 'Why don't people do it?'

South African participants had to find other, less satisfying ways to expose themselves to the spoken language. Catherine commented: "I listen to it [Chinese] when I am in the car because I have Chinese CDs." Annie does likewise: "I listen to CDs and repeat. Just like that - listen and repeat."

Clearly, oral communication inside and outside the classroom is an influential factor shaping the conservational proficiency of the two groups of participants. This was also borne out by the interview experiences in both countries. In China, the principal researcher (Wang) found that all participants spontaneously opted for Chinese as the medium for the interviews. She found that an Indonesian participant was already proficient in distinguishing geographical accents after a year in China: six months' study experience at a university in southern China and six months at another institution in northern China: "I can pick up a little on the accent of different people. The accents of people of the south and the people of the north are different. I find the southern accent easier to understand." Andong, an Indonesian student, was currently enrolled for a Master's in Chinese after completing his B-degree with CFL as major in China. He held strong convictions about the importance of a communicative environment in the development of conversational proficiency.

I really feel it is a big benefit for us to speak Chinese language everywhere. I had this experience in X University in my first year. I attended the students' association and I had to speak Chinese to converse with other Chinese students and my speaking skills improved vastly during that period. Then I didn't attend the students' association during my third and fourth years. One day I met a student who was in the students' association and he commented that my Chinese had deteriorated. I saw that if I do not keep contact with Chinese society, my skills fall behind.

Participants in China also recognised differing levels of competence in the CFL class, including their own. An Italian, Lisa, who had been Beijing for six months, noted: "I could read very well in the beginning [i.e. many characters], but the South Korean student could speak very well." Yilang, a Japanese student, reported: "Japanese students are better in reading and writing but less so in speaking. Russian students are better in speaking and they are confident to share their ideas and suggestions. I admire them for this." Participants also noted cultural differences among their international classmates regarding the confidence with which they used the new language. Thai student, Huilin, a secondyear student studying CFL for degree purposes, commented: "European students are very participative and make use of any opportunity [to express themselves]. Asian students are less inclined to participate actively."

In contrast, all South African participants lacked the confidence to use Chinese during the interviews; this applied to third-year students and even to Peter, who had ten years' of study experience behind him. However, many South African participants emphasised their progress in reading and writing skills. Linda said: "We have definitely done many characters so we will definitely be able to read a simple story in characters." Phumi added: "My reading is good, but speaking is bad. I understand if you speak slowly but when I have to speak, I get very nervous. It feels like I cannot say anything. You know, my head is blank, nothing inside. It is terrible. That is why I think it is better if you speak English to me [in this interview] so we can have a fluent conversation." Jill, enrolled in a Master's degree in Electronic Engineering, 
has had eight months of ancillary CFL study for non-degree purposes. She assessed her abilities: "We can read. Reading is much easier. So I think all of us can recognise the characters in Chinese and in our class we can read them. And I think in the test, we can also process what to do." Tony noted that his CFL lecturers in South Africa also emphasised reading and writing skills: "I feel the most important part for our lecturers is reading and writing. They did not teach us to speak in the first year. We have problems because many students cannot speak even in the third year, but they can read and write."

\subsection{The emotional dimension of learning a new language}

CFL study evoked similar emotions in participants interviewed in China and in South Africa. Enjoyment, excitement, warm appreciation of sympathetic lecturers and a sense of security engendered by lecturers' concern for their progress greatly encouraged language acquisition. Students who enjoy their studies persist with study and seek solutions to problems, even in the face of formidable challenges. A Thai student, Huilin, interviewed in China, described her emotional journey. At high school in Thailand, she had studied four languages: English, Japanese, French and Chinese. She only studied Chinese because her ancestral home is in China and her parents wanted her to study Chinese. Her grades were very poor in junior high school for all subjects. But gradually her grades for Chinese improved to the point where it became her best subject. Learning Chinese became a source of delight and fulfilment and she finally chose Chinese as her undergraduate major. She said: "I think the most important is that we persevere. I have a friend who likes Chinese very much like me... we have to set a goal and enjoy studying. Some students work very hard but they do not enjoy it and do not do well for that reason." Pastimes affiliated to Chinese, such as watching Chinese movies and television, added to the enjoyment of language learning. A fascination with Chinese culture was also a strong incentive. Peter, who is also a South African, persevered with CFL in spite of feelings of isolation because he has come to "love" Chinese and pleasure in language learning has outweighed his many disappointments.

All participants, both in China and in South Africa, commended their lecturers for their work ethic accompanied by a wealth of knowledge. Their lecturers' concern for student progress lent CFL students a sense of security and an emotional safety net, something that is nothing less than essential in any form of FL learning. Japanese Yilang, a participant in China, commented: "They [the lecturers] are certainly good. I want to give you an example: we have almost 20 students in one class. The lecturers care about every single one. I always get their attention in our class so I feel our lecturer cares about me."

Conversely, anxiety, poor confidence and disappointment frustrated students' attempts to learn and shaped participant decisions about continued CFL study in both country contexts. First attempts to speak the new language in class or in public were mingled with shyness and embarrassment. These were quickly overcome by the participants in China, because they experienced the benefits of immersion inside and outside the classroom. But South African participants were plagued by an ongoing sense of anxiety about speaking Chinese: as mentioned, none had the confidence to converse in Chinese during the interviews irrespective of the length of their CFL study. Students also experienced feelings of sadness and even loss, albeit for a variety of reasons. When CFL students in China were faced with a rigorous Chinese-only medium learning environment, they felt disempowerment in the absence of familiar language support. Several other participants in China also commented on the 'loss' of the taken-for-granted proficiency in their respective home language, which had no currency in the new environment. When South African participants took stock of their slow progress, they frequently felt pangs of self-reproach and considered dropping out of CFL study. In particular, Peter reflected on his decade of 'start-stop' CFL learning, a decade which has been punctuated by temporary interruptions in formal study. He said, "I was always sad to stop learning even if it was only for a short time until I found another suitable tutor or enrolled again for the formal university modules taken at Unisa for non-degree purposes."

\subsection{Academic 'push and pull'}

Participants in both country settings were energised by 'push and pull' factors: push exercised by pressure from lecturers in the form of regular homework assignments, formative tests and summative examinations, and pull exercised by relevant and interesting course material. In China, participants were required to spend about two or three hours on homework or assignments daily. However, this was not resented, it was preferred. Similarly, South African participants welcomed regular assignments and examinations and even wished for additional work. Annie said: "But I think it might be also nice if we have, like a sort of test before the exam, so we can prepare for final exam. Yes! yes!" Besides regular homework and testing, participants valued a disciplined learning environment created by institutional or lecturer requirements for regular class attendance, strict examination admission and firm deadlines for assignment submission. 
Where discipline was lax, students bemoaned the fact.

Participants in both countries were strongly motivated by instructional content relevant to their educational aspirations and useful in daily life. Andong, an Indonesian student in China, emphasised the importance of learning content that is related to future goals: "The courses are useful for us so we do not miss them. What we are taught is useful for our future." Vietnamese Amei also measured the success of her course against its usefulness in everyday life: "It is very useful because we learn the words that young people and local people use every day." In this regard, participants repeatedly referred to a learning vocabulary, such as colloquialisms, that enabled them to chat with native speakers, and they also referred to the need to become familiar with a variety of regional accents. CFL students in South Africa also appreciated content that was relevant and were hamstrung by the limited opportunities to test the relevance of content in informal conversation. Participants in both countries mentioned that certain textbook content was outdated or irrelevant to their lives.

In both country contexts, similar 'pull' was exercised by the extrinsic motivation to study CFL: the increasing importance of Chinese worldwide and the improved prospects for employment that Chinese proficiency implied. All participants in the study agreed that Chinese is a future world language and proficiency in Chinese would have an economic spinoff in the workplace. An Indonesia student, Ajiao, who is currently studying in China, commented: "My mother told me to study Chinese so I study it. For business reasons, English and Chinese both are very powerful languages." A South Korean student, Jin, who is currently studying in China, confirmed this motive: "Making money is the main reason for me to study because this language has more chance for business." In South Africa, Linda added: "I think that China is a big country and is involved all over the world, I think it is a very good language to be able to speak and communicate. I would really like to visit China one day. Yes!" Several participants in both countries aspired to find work as translators (Chinese to L1) or to find employment in large multinationals, given their proficiency in Chinese.

\subsection{Particular challenges of CFL acquisition: characters and tones}

Participants in both countries identified the recognition and reproduction of Chinese characters and the mastery of tones as the most challenging components of CFL learning. The non-alphabetical writing system makes learning Chinese characters an enormous challenge for FL learners, particularly for speakers of alphabetic systems. The struggle of English-speakers to acquire Chinese is due, in a large part, to the nature of its written orthography (Scrimgeour 2011). Specifically, its standard orthographic form does not readily indicate how Chinese characters are to be pronounced (Ye 2011). Participants in both country contexts found mastery of Chinese characters very difficult, particularly as far as writing was concerned.

The Chinese language has four principal tones which determine the meaning of a word (Zhang 2009). Words are either single syllable, or are made up by putting together two single-syllable words. Each syllable can have one of the four tones, and the tone or tones define the meaning of the syllable or word (Tsai 2011). Correct tonal pronunciation is therefore essential, as is the ability to distinguish tones when listening. There are a vast number of characters in Mandarin that have the same consonant and vowel sounds, but different tones. This is why tones are very important for both speaking and listening (Tsai 2011). Tones are very difficult for CFL students. This difficulty was identified by participants in both countries, as can be seen in these comments: "The most difficulty is the tones. It is definitely the tones!"; "The grammar of Chinese is not difficult but spoken and tones are difficult. New words are not difficult and we can practice but spoken and listening skills are difficult"; and "Pronunciation is difficult for me". This difficulty even applied to the participants who study in an immersion environment in China. South African CFL students are further impeded by the lack of opportunity to engage in and listen to conversations in Chinese.

\section{Discussion}

This paper has contrasted the lived experiences of international participants engaged in CFL study in Chinese universities and South African participants engaged in CFL study in their home institutions. Studying CFL in China constitutes a dominant SL setting (Siegel 2007; Baker 2001): students are immersed in Chinese culture, and Chinese is the medium of instruction in the classroom and medium of interpersonal communication out of class. Participants were thus immersed in "the rich bath of language" (Rigg \& Allen 1989: 144). This combination of formal study and natural language environment creates the optimal setting for FL language learning. In this case, learning CFL students have both the opportunity and the incentive to learn. This incentive to learn is based not only on intrinsic personal motivation, but also on the daily communicative demands which arise from living in China. Studying CFL in South African institutions comprises an external SL context (Siegel 2007; Baker 2001): students function in a 'lonely' language environment where 
the dominant language (usually English) is used as medium of instruction with limited code switching to Chinese in the classroom and out of class. Conversational practice is extremely limited, if it exists at all. CFL offered at Chinese universities thus falls into the category of an SL monolingual programme. CFL as offered at South African universities falls into the category of a L1 monolingual programme (Baker 2007).

Thus, participants studying in China enjoy several advantages over their South African counterparts who are studying at home. Lecture hours are longer; students are teamed up with native speaking peer tutors; in class, students are forced to use Chinese as the lingua franca and classroom attendance is stable, which promotes the formation of a "language community" (Skutnabb-Kangas 2008). In addition to all this, courses follow the four-skill approach, and language immersion is continued in the community. Participants in China are definitely enabled to meet Curtain's (2013) recommendation that FL learners should use the target language $90 \%$ of the time to reap optimal results. In South Africa, Chinese lectures compete with other academic offerings on the timetable; tutors are not peers and a tutor services a whole class not an individual; apart from all this, the opportunity to engage in social interaction with native speakers is missing. Thus, South African participants have to expend far greater energy in pursuit of their language interest and their perseverance is noteworthy. These findings clearly highlight the value of language study abroad as the most efficient way to study a foreign language.

Having said that, participants in both settings shared many experiences inherent to FL learning. Their remarks showed that the affective nature of language learning impacted CFL acquisition, both positively and negatively as Dewaele (2011) confirms. The experience of learning Chinese was both exciting and intimidating; students were empowered as they discovered new skills and, at the same time, overwhelmed by embarrassment and shyness (Horwitz 2010). All participants recognised the incentive of a disciplined and structured learning environment with regular assignments and testing, the so-called 'push' exercised by lecturers (Lu \& Zhao 2011). Participants interviewed in both countries also shared the reasons given for the study of Chinese: the rising status of Chinese; employment prospects and idiosyncratic fascination with China and its culture. Similarly, challenges inherent in the language regarding mastery of written characters and tones were encountered by all participants, something that is borne out by other studies (Cruikshank \& Tung 2011; Scrimgeour 2011; Tsai 2011).

\section{Conclusion}

This paper explored students' experience of learning CFL in China and South Africa, two contrasting socio-linguistic settings that illustrate both the differences and commonalities in FL language learning. In sum, differences in student experiences were chiefly embedded in the language learning context and the type of programme and less in the individual learner. The findings are particularly useful for the insight they provide into students' experience of CFL when these students are limited to the classroom contexts of home institutions, without access to a natural learning environment.

\section{References}

Baker, C. (2001). Foundations of Bilingual Education and Bilingualism. 3rd ed. Clevedon: Multilingual Matters.

Baker, C. (2007). Bilingual Education. Clevedon: Multilingual Matters.

Charmaz, K. (2011). Grounded theory methods in social justice research. In: Handbook of qualitative research $4^{\text {th }}$ ed. Edited by Denzin, N. K. \& Lincoln, Y. E. Thousand Oaks: Sage.

Collentine, J., \& Freed, B. (2004). Learning context and its effects on second language acquisition. Studies in Second Language Acquisition, 26 (2), 153-171.

Crystal, D. (2010). The Cambridge Encyclopaedia of Language. 3rd Edition. Cambridge: Cambridge Press.

Cruickshank, K., \& Tsung, L. (2011). Teaching and learning Chinese. London : Continuum International Publishing Group.

Curtain, H. (2013). Teaching in the target language. Available at:

http://nclrc.org/about_teaching/topics/PDFs/FeatureCurtain-TeachingintheTargetLanguageFINAL.pdf Accessed 14 June, 2013.

Dewey, D. (2008). Japanese vocabulary acquisition by learners in three contexts. Frontiers: The Interdisciplinary Journal of Study Abroad, 25, 127-148.

Dewaele, J. M. (2011). Reflections on the emotional and psychological aspects of foreign language learning and use. Anglistik: International Journal of English Studies. 22,1.

Fashold, R., \& Cornor-Linton, J. (2006). An Introduction to Language and Linguistics. Cambridge University Press: Cambridge.

Feng, L. (2008). Overview of Chinese language teaching in South Africa [Translated by Wang, Y] Journal of International Chinese Teaching and Development BFSU. 3, 1-7.

Freed, B. (ed.) (1995). Second language acquisition in a study abroad context. Amsterdam: John Benjamin.

Freed, B., \& Lazar, N. (2003). Language learning abroad. ADFL Bulletin 34 (3), 34-40. 
Garcia, O. (2009). Bilingual Education in the 21st Century. New York: Wiley-Blackwell.

Healy, F., \& Bourne, L. E. (1998). Foreign Language Learning. Mahwah: Erlbaum.

Horwitz, E. K. (2010). Foreign and second language anxiety. Language Teaching 43,154-167.

Lu, J., \& Zhao, Y. (2011). Teaching Chinese as a foreign language in China: A profile. In Teaching and learning Chinese in global contexts, edited by L. Tsung \& K. Cruickshank. London: Continuum International Publishing Group.

Lytra, V., \& Martin, P. (2010). Sites of multilingualism. Stoke-on Trent, England: Trentham Books, 19-32.

Mackey, W. F. (2008). A typology of bilingual education. Foreign Language Annals, 3(4). Available at: DOI: 10.1111/j.19449720.1970.tb01307.x Accessed 28 February, 2014.

McMillan, J. H., \& Schumacher, S. (2010). Research in education. 7th Edition. Boston: Pearson Education.

Park, Y. K. (2012). Living in between: The Chinese in South Africa. Available at: http://www.migrationinformation.org. Accessed 28 January, 2014.

Qian, X. (1999). Hanwai yuyan duibi, pianwu fenxi, zhongjieyu he di er yuyan xide lilun cankao wenxian (1977-1998) (Translated: Bibliography: Contrastive analysis of Chinese and foreign languages, error analysis, interlanguage and second language acquisition theories). In Hanwai yuyan duibi yu pianwu fenxi lunwen ji. (Translated: Chinese and foreign languages: the collection of contrastive and error analysis papers). Edited by Q. Zhang \& S. Wang. Beijing: Beijing University Press.

Richards, J. C., \& Schmidt, R. (2002). Longman dictionary of language teaching and applied linguistics. $3^{\text {rd }}$ edition. London: Longman.

Rigg, P., \& Allen, V. G. (1989). When they don't all speak English. Urbana: NCTE.

Sasaki, M. (2009). Changes in English as a foreign language students' writing over 3.5 years. In Foreign Language Contexts, edited by R. Manchón. Clevedon: Multilingual Matters.

Saville-Troike, M. (2012). Introducing second language acquisition. Cambridge: Cambridge University Press.

Scrimgeour, A. (2011). Issues and approaches to literacy development in Chinese second language classrooms. In Teaching and Learning Chinese in Global Contexts, edited by L. Tsung \& K. Cruickshank. London: Continuum International Publishing Group.

Siegel, J. (2007). Social Context. In Handbook of Second Language Acquisition, edited by C. J. Doughty \& M. H. Long. Oxford: Blackwell Publishing.

Skutnabb-Kangas, T. (2008). Language rights and bilingual education. In Cummins, J \& Hornberger, N (eds) Bilingual Education. New York: Springer.

Statistics South Africa, (2013). Mid year population estimates 2013. Available at: www.statssa.gov.za. Accessed 5 February, 2014.

Tsai, R. (2011). Teaching and learning the tones of Mandarin Chinese. Scottish Languages Review. Available at: http://www.scilt.org.uk/Portals/24/Library/str/issues/24/ 245 Tsai.pdf Accessed 2 August, 2013.

Van Patten, B. (1990). Theory and research in second language acquisition and foreign language learning. In Second language acquisition/foreign language learning, edited by B. J. Van Patten \& F James. Clevedon: Multilingual Matters.

Van Patten, B., \& Williams, J. H (eds.). (2007). Theories in second language acquisition. New York: Routledge.

Xu, Y., Chang, L., Zhang, J., \& Perfetti, C. A. (2013). Reading, writing and animation in character learning in Chinese as a Foreign Language. Foreign Language Annals, 14(3), 423-444.

Wang, D., Moloney, R., \& Li, Z. (2013). Towards Internationalising the Curriculum: A Case Study of Chinese Language Teacher Education Programs in China and Australia. Australian Journal of Teacher Education, 38(9), Article no.8.

Wang, Y., \& Lemmer, E. (2013). The provision of Mandarin as a foreign language in higher education institutions in South Africa. Per Linguam, 29(1), 33-48.

Wang, Y. (2013). A Comparative study of Mandarin as a Foreign Language in China and South Africa at Higher Education. Unpublished doctoral thesis. Pretoria, University of South Africa.

Ye, L. (2011). Teaching and learning Chinese as a foreign language in the United States. Unpublished thesis, Georgia State University. Available at: http://digitalarchive.gsu.edu.alesl diss Accessed 1 August, 2013

Zhang, H. (2009). Road to success. Beijing: Beijing Lānguage and Culture University Press. 